\title{
Photoemission Study of Bi-System High-Tc Superconductor
}

\section{B i 系高温招卮導体の光電子分光}

\author{
Takashi Takahashi and Toshiaki Kusunoki \\ Department of Physics, Tohoku University, Sendai 980, Japan \\ TEL: $022-222-1800 \quad$ FAX: $022-225-1891$ \\ (Received 30, May 1991 Accepted 19, June 1991) \\ ABSTRUCT \\ Angle-resolved photoemission study on hole-concentration dependence \\ in $\mathrm{Bi}_{2} \mathrm{Sr}_{2} \mathrm{CaCu}_{2} \mathrm{O}_{8} \mathrm{high-Tc}$ superconductor has been reported. The result \\ clearly shows that (1) there exist two large Fermi surfaces as predicted \\ from the band structure calculation, (2) the Fermi liquid states giving \\ such large Fermi surfaces are formed by hole-doping, and (3) the hole- \\ doping does not necessarily cause a rigid shift of the Fermi level but \\ creats new electronic states in the charge-transfer gap.
}

Key Words : high-Tc superconductor, photoemission, electronic structure, Fermi surface.

\section{1 はじめに}

酸化物高温超伝導体の超伝導発現機構を解明 し、さらに高い超伝導転移温度を持つ新物質提 案の指針を与えるためには、そのクーパー対形 成の舞台であるフェルミ準位近傍の電子状態を 明らかにする必要がある。光電子分光は、電子 状態を直接観測できるという点で非常に強力な 実験手段であり、高温超伝導体発見の初期から 積極的に適用され、高温超伝導体の電子構造解 明に大きく貢献している。さらに最近は、高工 ネルギー分解能化、低温での测定が進み、超伝 導ギャップの直接観測の報告もある。本稿では、 酸化物高温超伝導体の光電子分光、逆光電子分 光研究の現状を説明し、それらに基づいて高温 超伝導体の電子状態について考察したい。

\section{2 光電子分光法}

物質に光を入射すると外部光電効果により占 有準位にあった電子が真空中に放出される。 Figure 1 に示すように、入射する光のエネル ギーを方山、放出された電子の運動エネルギー を Ek、放出された電子が物質中にあった時の結 合エネルギー（フエルミ準位からのエネルギー） を $E_{B}$ すると、その間には

$$
\hbar \omega=\mathrm{E}_{k}+\mathrm{E}_{8}+\phi
$$

のエネルギー保存則が成立する。ここでめは物 質の仕事関数（フェルミ準位と真空準位のエネ ルギー差）で、物質固有の量である。従って、 真空中に飛び出した電子の運動エネルギーE と その強度を測定することにより、物質中の電子 状態を直接調べることができる。角度分解光電 


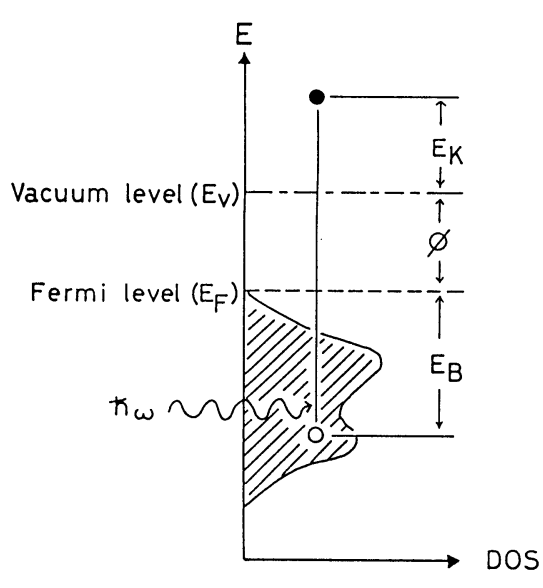

Fig.1 Schematic diagram of photoemission spectroscopy. The energy-conservation law, $\hbar \omega=\mathrm{Ek}+\mathrm{EB}+\phi, \quad$ is established.

子分光法とは単結晶表面から放出された光電子 の立体角中への放出分布を測定するもので、電 子が単結晶表面を通過する際、運動量の表面平 行成分が保存することを利用して、単結晶の二 次元的バンド分散を描き出すことができる。1

高温超伝導体、とりわけB i 系高温超伝導体は 強い2 次元性を持ち、単結晶表面に垂直な方向 にはほとんどバンド分散はないと考えられる。 このことが高温超伝導体研究において光電子分 光の有用性をさらに高めている。角度分解光電 子分光測定には励起光として真空紫外領域の励 起光を使う。この領域の光で励起された光電子 の固体内での平均自由行程は非常に短く、10 〜 $100 \AA$ 程度であり表面の状態に非常に敏感 である。そのため超高真空下でのへき開などに よる清浄な試料表面の作成が必要となる。

$3 \mathrm{~B} \mathrm{i}_{2} \mathrm{~S} \mathrm{r}_{2} \mathrm{C} \mathrm{a} \mathrm{C} \mathrm{u}{ }_{2} \mathrm{O}_{8}$ の角度分解光電子 分光

角度分解光電子分光を行うためには、平坦な 表面を持つ比較的大きな単結晶が必要である。 我々はf $1 \mathrm{u} \times$ 法により $5 \times 5 \times 0.2 \mathrm{~m} \mathrm{~m}^{3}$ ほど の $\mathrm{B} \mathrm{i}_{2} \mathrm{~S} \mathrm{r}{ }_{2} \mathrm{C} \mathrm{a} \mathrm{C}_{2} \mathrm{O}_{8}$ 単結晶を育成した。 まず $\mathrm{B} \mathrm{I}_{2} \mathrm{O}_{3} 、 \mathrm{~S} \mathrm{r} \mathrm{C} \mathrm{O}_{3} 、 \mathrm{CaC}_{3}$ 、及び C u O 粉末を化学量論比で混合したものに、約 20 重量\%のKC 1 を $\mathrm{f} 1 \mathrm{u}$ ×として加え、混 合し、白金るつ卧中で $890^{\circ} \mathrm{C}$ に加熱した後、 〜 $0.5^{\circ} \mathrm{C} / \mathrm{h}$ の割合で $850^{\circ} \mathrm{C}$ まで徐冷し、
炉冷したものである。 $\mathrm{B} \mathrm{i}_{2} \mathrm{~S} \mathrm{r}{ }_{2} \mathrm{C} \mathrm{a} \mathrm{C} \mathrm{u}{ }_{2} \mathrm{O}_{3}$ 単結晶であることはX線回折により確認した。

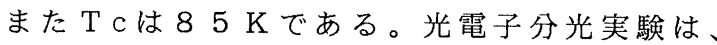
分子科学研究所シンクロトロン放射光実験施設

( UV S O R ) のB L - 8 B 2 で行い、エネル ギー及び角度分解能はそれぞれ $0.2 \mathrm{e} \mathrm{Vと} 2^{\circ}$ である。測定試料表面は超高真空中でのへき開 によって得た。フェルミ準位の決定は測定後、 試料上に金を蒸着し、そのフェルミ準位を基準 にした。

角度分解測定は、 $\mathrm{B} \mathrm{i}_{2} \mathrm{~S} \mathrm{r}{ }_{2} \mathrm{C}$ a $\mathrm{Cu}_{2} \mathrm{O}_{8}$ を 斜方晶系と見たときのブリルアンゾーン中の対 称性の高い $\Gamma-\mathrm{X}(\mathrm{Y}) 、 \Gamma-\overline{\mathrm{M}}$ 方向で行った。 $\Gamma-\mathrm{X}(\mathrm{Y})$ 方向は、 $\mathrm{C} \mathrm{u} \mathrm{O}_{2}$ 面内の $\mathrm{Cu}-\mathrm{Cu}$ 、 あるいは O-Oの結合方向であり、 $\Gamma-\bar{M}$ 方向は C u-Oの結合方向に対応している。しかしなが ら、 $\mathrm{B} i$ 系では $\mathrm{a}$ 軸と $\mathrm{b}$ 軸の長さはほぼ同じで あり正方晶系に非常に近いため光電子分光では $\Gamma-\mathrm{X}$ と $\Gamma-\mathrm{Y}$ 方向は区別できない。

Figure 2 に $\mathrm{Bi}_{2} \mathrm{~S} \mathrm{r}_{2} \mathrm{C}$ a $\mathrm{Cu}_{2} \mathrm{O}_{8}$ 単結晶の 角度分解光電子分光スペクトルを示す。2 スペ クトル中にはいくつかの構造 $(\mathrm{A} \sim \mathrm{F})$ が見い 出される。ここで注目すべきは、スペクトル中 に明らかなフェルミ端構造が観測されることで ある。
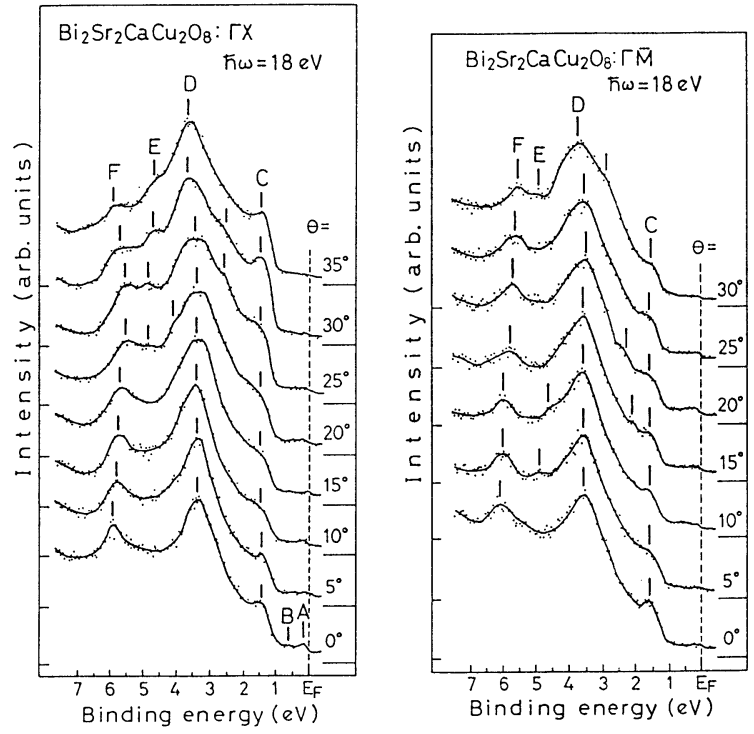

Fig.2 Angle-resolved photoemission spectra of $\mathrm{Bi} 2 \mathrm{Sr} 2 \mathrm{CaCu} 2 \mathrm{O} 8$ measured at $\hbar \omega=18 \mathrm{eV}$. Poler angle $(\theta)$ referred to the surface normal is indicated on each spectrum. 

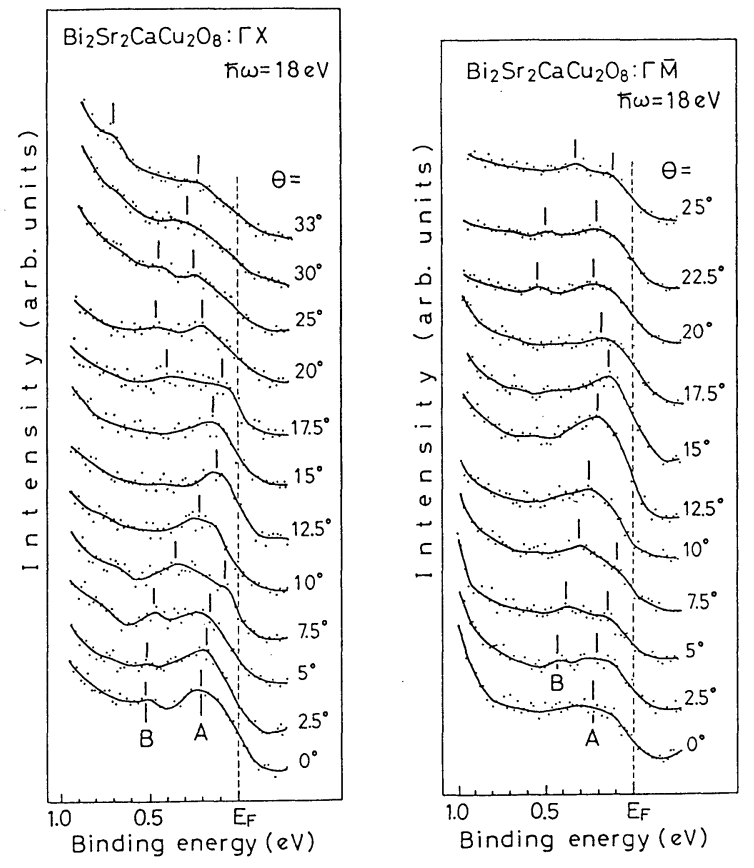

Fig.3 Angle-resolved photoemission spectra of $\mathrm{Bi} 2 \mathrm{Sr} 2 \mathrm{CaCu} 2 \mathrm{O} 8$ in the vicinity of the Fermi level. Two bands crossing the Fermi level are observed.

Figure 3 にフェミミ準位近傍を拡大して測定 したスペクトルを示す。 2 本のバンド $\mathrm{A} 、 \mathrm{~B}$ が 明確なエネルギー分散を示していることがわか る。 $\Gamma-\mathrm{X}$ 方向においてはバンド $\mathrm{A}$ が $\theta=7.5^{\circ}$ で、バンド $\mathrm{B}$ が $\theta=17.5^{\circ}$ で、また $\Gamma-\overline{\mathrm{M}}$ 方 向でもバンド $\mathrm{A}$ が $\theta=7.5^{\circ}$ でフェルミ準位 を横切っているように見える。Figure 2、3の 角度分解光電子分光スペクトルから求められる

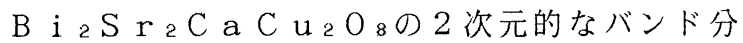
散を描いたものがFigure 4である。バンドAは $0.2 \mathrm{e} \mathrm{V}$ 程度のバンド分散を示し $\Gamma$ 点を離れる とすぐフェルミ準位を切っているように見える。 またバンド B は約 $0.5 \mathrm{eV}$ の分散を示し、「点 とX点の中点付近でフェルミ準位を切っている。 これらの事はB i 系高温超伝導体において、バ ンド計算から予測されているような「大きな」 フェルミ面が存在していることを示唆している。 このようなフェルミ端構造は、細かな違いはあ

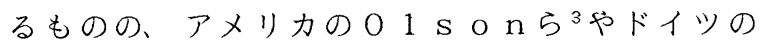

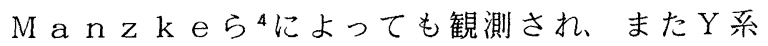
などの他の高温超伝導体でも観測されている。 このことは高温超伝導体に明確なフェルミ面が

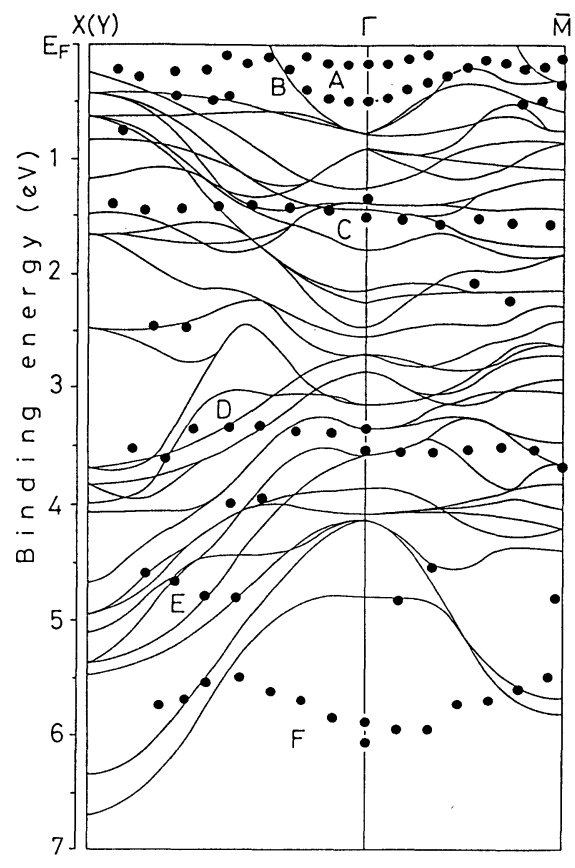

Fig.4 Band structure of $\mathrm{Bi} 2 \mathrm{Sr} 2 \mathrm{CaCu} 2 \mathrm{O} 8$ determined by the present angle-resolved photoemission study. Thin solid lines show the band structure calculation by Massidda et al.?

存在し、超伝導発現機構を理解する上でフェル ミ液体状態を出発点とするアプローチの正当性 を示している。

4 ホールのドープ量を変化させた

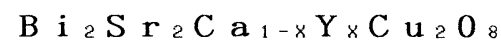
$(x=0.4 、 0.6)$ の角度分

\section{解光電子分光}

非超伝導体（絶縁体）から超伝導体への転移 における電子状態の変化を調べることは、フェ ルミ液体状態形成の起源を探る上で重要である。 $\mathrm{B} \mathrm{i}_{2} \mathrm{~S} \mathrm{r}{ }_{2} \mathrm{Ca} \mathrm{C} \mathrm{u}{ }_{2} \mathrm{O}_{8}$ 単結晶はas-grownの段 階で過剩酸素のため既にホールがドープされ超 伝導体となる。ホール濃度のコントロールは、 2 価の $\mathrm{C}$ aを 3 価の $\mathrm{Y}$ で置換することにより 行った。単結晶 $\mathrm{B} \mathrm{i}_{2} \mathrm{~S} \mathrm{r}_{2} \mathrm{C} \mathrm{a}_{1-x} \mathrm{Y} \times \mathrm{Cu}_{2} \mathrm{O}_{8}$ $(\mathrm{x}=0.4 、 0.6)$ は $\mathrm{B} \mathrm{i}{ }_{2} \mathrm{O}_{3} 、 \mathrm{C} \mathrm{a} \mathrm{C} \mathrm{O}_{3}$ 自身を $f$ luxとする $\mathrm{x}$ e $l f-f l u x$ 法で 育成した。育成した単結晶中の $\mathrm{Y}$ と $\mathrm{C}$ a の組成 比は、EPMA（Electron-Probe-MicroAnalysis）およびc 軸の格子定数の測定（Yの 

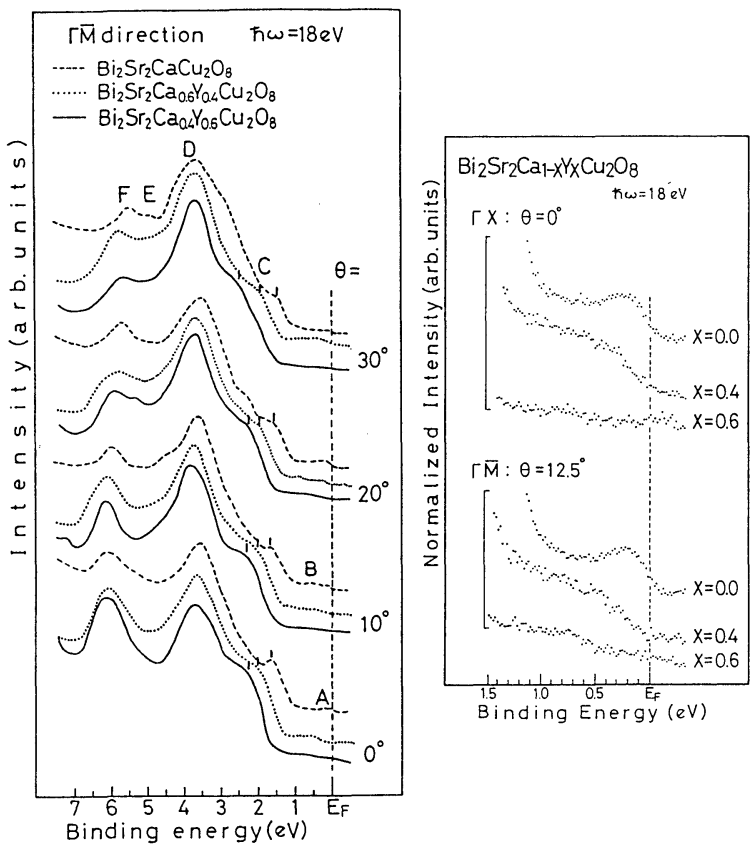

Fig.5 Comparison of representative angle-resolved photoemission spectra of $\mathrm{Bi} 2 \mathrm{Sr} 2 \mathrm{Ca} 1-\mathrm{x} \mathrm{YxCu}_{2} \mathrm{O} 8$ $(\mathrm{x}=0.0,0.4$, and 0.6$)$

ドープ量によってc 軸の長さが変わる) から求 めた。電気抵抗および帯磁率の測定から、 $\mathrm{x}=$ 0.6 の単結晶は非超伝導体（絶縁体）、 $\mathrm{x}=$ 0.4 の単結晶は $\mathrm{T}=50 \mathrm{~K}$ 付近で一度抵抗の 減少がみられるものの、さらに低温で再び抵抗 が増加し、超伝導体と非超伝導体の境界付近の 組成であると考えられる。

Figure $5 \mathrm{RB} \mathrm{i}_{2} \mathrm{~S} \mathrm{r}_{2} \mathrm{C}_{\mathrm{a}_{1-x}} \mathrm{Y}_{x} \mathrm{Cu}_{2} \mathrm{O}_{8}$ $(\mathrm{x}=0.0 、 0.4 、 0.6)$ の価電子帯とフェ ルミ準位付近の角度分解光電子分光スペクトル の比較を示す。非超伝導体 $(\mathrm{x}=0.6)$ 加ら超 伝導体 $(x=0.0)$ への变化（ホールのドープ 量の增加）に伴い、結合エネルギー $2.2 \mathrm{eV}$ $1.4 \mathrm{eV}$ に見られる肩構造 (バンドC) が連続 的に0.8 e V 程度フェルミ準位に近い方へシフ トしている。一方染い結合エネルギーの領域 (バンド $\mathrm{D} \sim \mathrm{F})$ は、多少 $(\sim 0.2 \mathrm{e} \mathrm{V})$ のシ フトはあるもののバンドCのような顕著な变化 は見られない。 $\mathrm{x}=0.6$ ではフェルミ準位近傍 に全く電子状態は観測されない。ホールが偉か にドープされた $\mathrm{x}=0.4$ では、フェルミ準位よ り少し離れた位置にブロードなピークが観測さ れ、絶縁体のギャップ中に新たな電子状態が成 長していることがわかる。さらにホールがドー プされ、超伝導体となった $\mathrm{x}=0.0$ ではフェル

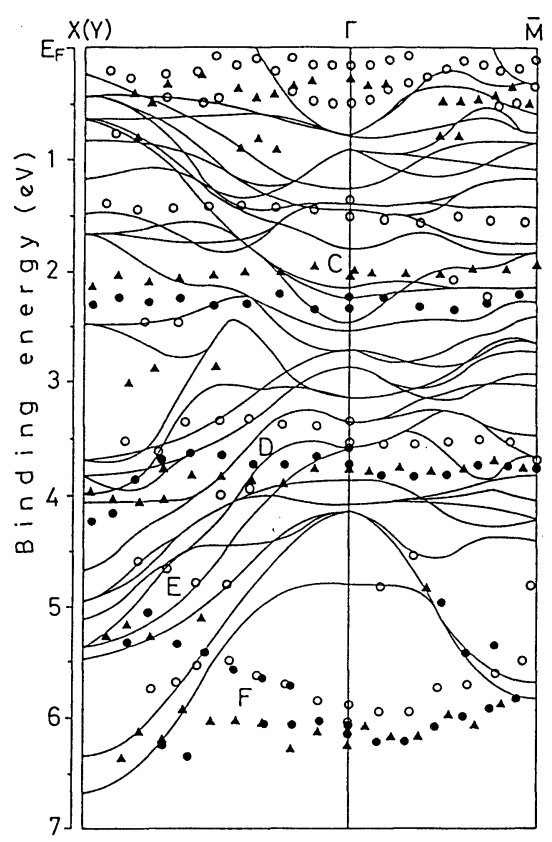

Fig.6 Band structure of $\mathrm{Bi} 2 \mathrm{Sr} 2 \mathrm{Ca} 1-\mathrm{x} \mathrm{YxCu} 2 \mathrm{O} 8$ $(\mathrm{x}=0.0,0.4$, and 0.6$)$ determined by angle-resolved photoemission. Symbols $\bigcirc, \boldsymbol{O}$ and $\boldsymbol{\Delta}$ represent the results for $\mathrm{x}=0.0,0.4$, and 0.6 , respectively.

ミ準位近傍に系の金属的性格を示す大きな電子 状態密度が観測される。次に角度分解光電子分 光から求めた $\mathrm{B} \mathrm{I}_{2} \mathrm{~S} \mathrm{r}_{2} \mathrm{C} \mathrm{a}_{1-x} \mathrm{Y} \times \mathrm{Cu}_{2} \mathrm{O}_{8}$ $(\mathrm{x}=0.0 、 0.4 、 0.6)$ のバンド分散の比 較をFigure 6 に示す。高結合エネルギー領域の バンド D、E、Fは非超伝導体一超伝導体転移 において特に大きな変化は示さない。一方、低 結合エネルギー領域のバンド C はホールのドー プ量の増加に伴いフェルミ準位側へ顕著なシフ 卜を示している。フェルミ準位近傍においては、 $\mathrm{x}=0.6$ の試料で全く電子状態は観測されない が、 $\mathrm{x}=0.4$ ではフェルミ準位より少し離れた 位置に僅かに分散を示すバンドが観測され、さ らにホールがドープされ超伝導体 $(\mathrm{x}=0.0)$ になると、フェルミ準位を切る明確なエネル ギー分散を示す 2 本のバンド $\mathrm{A} 、 \mathrm{~B}$ が出現する。

このように非超伝導体一超伝導体転移に打け る電子状態の変化は、ホールのドープによって フェルミ準位付近に新たな電子状態が形成され ることによって引き起こされていることがわか る。?またフェルミ準位付近のバンド $\mathrm{A} \sim \mathrm{C}$ は 共鳴光電子分光 ${ }^{2}$ 、軟 $X$ 線吸収分光 ${ }^{7}$ からいず机 も $\mathrm{O}-2 \mathrm{p}$ 的性格が強いバンドであることがわか つている。 
光電子分光における高エネルギー分解能化は 高温超伝導体の超伝導ギャップの直接観測を可 能にした。Figure 7 に B i $2 \mathrm{~S} \mathrm{r}{ }_{2} \mathrm{C}$ a $\mathrm{C} \mathrm{u}_{2} \mathrm{O}_{8}$ について、超伝導転移点 $T_{c}$ の上下で测定した角 度分解光電子スペクトルを示す。 ${ }^{3} \mathrm{~T}$ cより上の 温度ではフェルミ準位上に有限な電子状態密度 が観測されるが、Tcより下の温度ではフェルミ 準位上の状態密度は減少し、逆にフェルミ準位 よりやや低結合エネルギーの状態密度が増加し ている事がわかる。この变化は、超伝導転位点 温度の下で超伝導ギャップが開いている事を直 接示しているものである。これをB C S 的な等 方的超伝導ギャップと考えると $2 \Delta / \mathrm{k}_{\mathrm{B}} \mathrm{T}_{\mathrm{c}} \sim 7$ であり、B C S 弱結合理論の值 3.5 上りもはる かに大きく、高温超伝導体が強結合領域にある ことを示唆している。

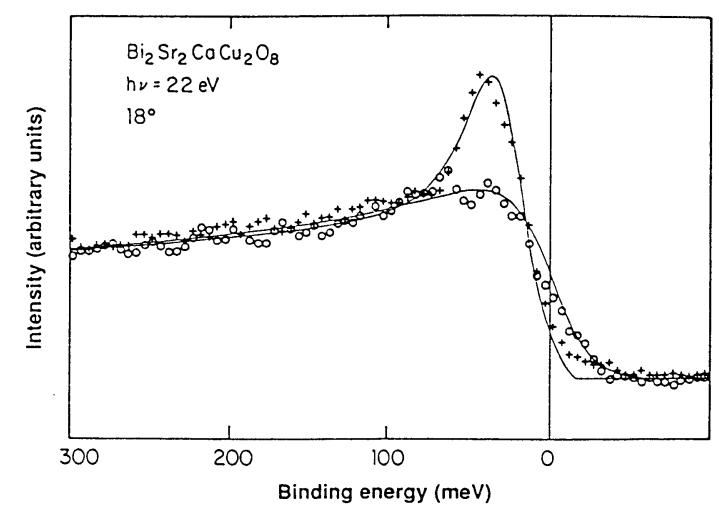

Fig.7 Angle-resolved photoemission spectra of $\mathrm{Bi} 2 \mathrm{Sr} 2 \mathrm{CaCu} 2 \mathrm{O} 8$ taken at temperatures above (open circles) and below (crosses) Tc. ${ }^{3}$ Opening of the superconducting gap is observed.

\section{6 逆光電子分光}

逆光電子分光法は、外部光電効果の逆過程を 利用して、物質の非占有電子状態を調べる最も 直接的な方法である。8とりわけ、フェルミ準 位近傍の電子状態を調べる場合には、光電子分 光と逆光電子分光の併用が強力な手段となる。 Figure 8 に、B i 系超伝導体で C a して、ホール濃度を変化させた焼結体試料につ
いての逆光電子スペクトルを光電子スペクトル と比較して示す。非超伝導体 $(x=0.5)$ では ほとんど見られないフェルミ準位近傍のスペク トル強度が、ホールのドープ量の増加に伴い単 調に増加することがわかる。注目すべき事は、 ホールのドーピング量の変化によって、非占有 電子状態から占有電子状態への電子状態の移動、 さらにその逆過程も観測されないことである。 このことは、光電子分光の結果でも推測された が、ホールのドープによりフェルミ準位のシフ トは起きず、ギャップ中に新たな電子状態が形 成されることを示している。

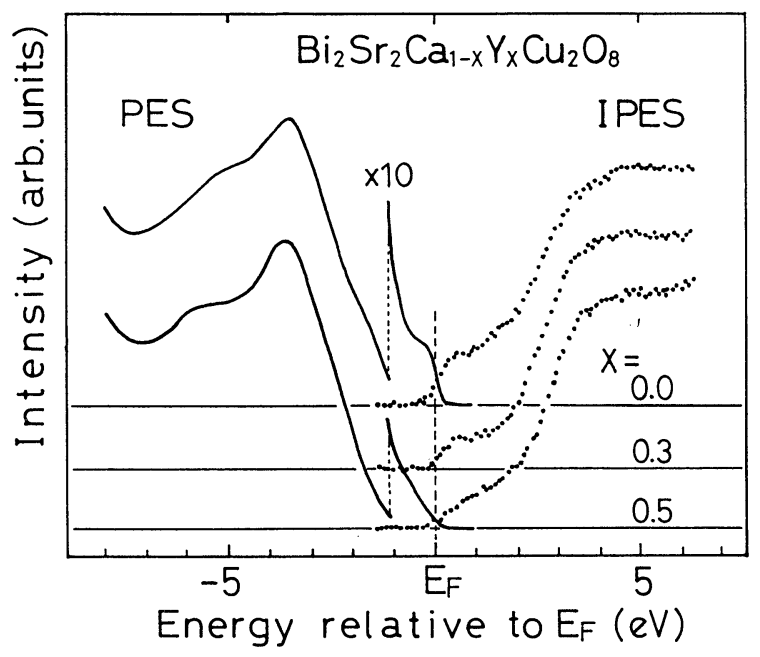

Fig.8 Comparison of photoemission and inverse photoemission spectra of $\mathrm{Bi} 2 \mathrm{Sr} 2 \mathrm{Ca} 1-\mathrm{xY} \times \mathrm{Cu} 2 \mathrm{O} 8$ $(x=0.0-0.5)$. Hole doping creates new electronic states in the vicinity of the Fermi level.

\section{7 高温超伝導体の電子構造}

以上の光電子分光、逆光電子分光実験の結果 から導かれる高温超伝導体の非超伝導体一超伝 導体転移の電子状態の模式図をFigure 9 に示す。 非超伝導体においては強い $\mathrm{Cu}-3 \mathrm{~d}$ 電子間の クーロン反発力によりモットーハバードギャッ プが開き、その間に0-2 p 占有準位が位置する ことから、約 $2 \mathrm{e} \mathrm{V}$ 程度の電荷移動ギャップが 形成される（Figure9（a））。ホールがドー プされると（b）（c）に示すようにギャップ 
中に新しい電子状態が形成される。この新しい mid-gap-statesは、ホールがドープされること により初めて形成され、さらにその強度がホー ルのドープ量に相関するという意味で、一種の 不純物準位と見なすことができる。このmidgap-s tates は共鳴光電子分光、軟 $X$ 線吸収分光 実騟から強い $0-2 \mathrm{p}$ 的性格を持っていることが わかっている。また、ホールのドーピングによ り、バンドCがフェルミ準位に近づくと同時に、 新たに形成された電子状態の重心もフェルミ準 位に近付くことが観測される。さらにホールが ドープされ系が超伝導体になると（d）、フェ ルミ準位を切るような 2 本のバンド A、Bが出 現し「大きな」フェルミ面を形成する。このよ うにして高温超伝導発現の舞台となるフェルミ 液体状態が形成されるものと考えられる。高温 超伝導はこのフェルミ液体状態中のホール（ま たは電子）が強い電子一格子相互作用を媒介と して、クーパー対を形成することにより引き起 こされるものと推測される。

\section{8 おわりに}

光電子分光をはじめとする高エネルギー分光 による酸化物高温超伝導体の研究は世界中で精 力的に行われており、大きな成果を挙げている。 フェルミ液体状態や超伝導ギャップの存在はす でに多くのグループによって確認され、実験的 には既に確立したと言える。しかしながら、電 子相関の影響がどの程度大きいのか、またバン ド計算がどこまで正しいのかという点について は各実験グループの間で立場が異なる。高温超 伝導発現機構解明に最終的な結論を与えるため には、より高分解能で精度の良い、系統的な実 験が必要である。

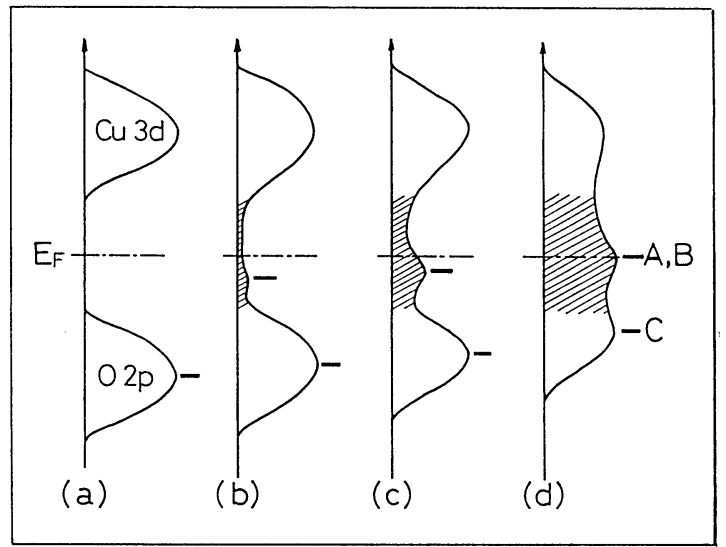

Fig.9 Schematic diagram of the electronic structure and formation-process of the Fermi-liquid states in $\mathrm{Bi}$ system high-Tc superconductor.

\section{REFERENCES}

${ }^{1}$ T. Takahashi, Solid State Physics 24, 391 (1989) (in Japanese).

${ }^{2}$ T. Takahashi et al., Nature 334, 691 (1988).

${ }^{3}$ C.G.0lson et al., Science 245,731 (1989).

${ }^{4}$ R. Manzke et al., Physica C 162, 1381 (1989).

${ }^{5}$ J.C.Campuzano et al., Phys. Rev. Lett. $64,2308(1990)$.

${ }^{6} \mathrm{~T}$. Takahashi et al., Physica C 170 , 416(1990).

${ }^{7}$ H.Matsuyama et al., Physica C 160 , 567(1989).

${ }^{8}$ T. Takahashi, Solid State Physics 23, 397 (1988) (in Japanese). 